\title{
AFLP Analysis of Intraspecific Variation Between Monilinia laxa Isolates from Different Hosts
}

Tjasa Gril, Centre for Plant Biotechnology and Breeding, Biotechnical Faculty, Jamnikarjeva 101, 1000 Ljubljana, Slovenia; Franci Celar, Entomology and Phytopathology, Biotechnical Faculty, Jamnikarjeva 101, 1000 Ljubljana, Slovenia; Alenka Munda, Plant Protection Department, Agricultural Institute of Slovenia, Hacquetova 17, 1000 Ljubljana, Slovenia; and Branka Javornik and Jernej Jakse, Centre for Plant Biotechnology and Breeding, Biotechnical Faculty, Jamnikarjeva 101, 1000 Ljubljana, Slovenia

\begin{abstract}
Gril, T., Celar, F., Munda, A., Javornik, B., and Jakse, J. 2008. AFLP analysis of intraspecific variation between Monilinia laxa isolates from different hosts. Plant Dis. 92:1616-1624.

We analyzed with an amplified fragment length polymorphism (AFLP) marker system the genetic diversity and relationships among 67 Monilinia laxa isolates obtained from different host plants. From a total of 1,089 amplified bands scored using 20 primer combinations with two selective nucleotides, 354 were polymorphic and further used in genetic diversity analysis. Genetic relationships among isolates were assessed with different phenetic approaches, including unweighted pair group method with arithmetic mean clustering and principal coordinate analysis; the population's differentiation estimate was analyzed by molecular variance; and modelbased clustering was employed to infer population structure. All four analyses clearly showed significant differences between isolates from apple trees and isolates from other host plants. No further grouping according to any other host plant was observed. The results indicate host specialization of apple isolates and support the taxonomic grouping of apple isolates.
\end{abstract}

Additional keywords: forma specialis, molecular markers

Assessment of the level and nature of genetic variation in plant pathogenic fungi has important implications in disease management and understanding host-pathogen interactions. Brown rot of fruit crops caused by species of the genus Monilinia is an extremely destructive disease found in most temperate regions in which apples, pears, and other rosaceous fruit trees are grown (2,3). They cause considerable losses to fruit crops and damage trees (39).

The genus Monilinia includes three most widely known and economically important species: M. fructigena Honey, M. fructicola (G. Winter.) Honey, and $M$. laxa (Aderh. \& Ruhl.) Honey. Although the three species are polytrophs and infect a wide range of Rosaceae species, a certain level of host specialization exists among them. M. fructigena is mainly a fruit rot pathogen, although it is also able to infect and colonize blossoms and it occurs predominantly in pome fruit orchards. $M$. fructicola is mostly confined to stone fruits-peach, nectarine, plum, and apricots-and is mainly a fruit pathogen. $M$. laxa is a blossom and twig pathogen, caus-

Corresponding author: Jernej Jakse

E-mail: jernej.jakse@bf.uni-lj.si

Accepted for publication 14 August 2008.

doi:10.1094/PDIS-92-12-1616

(C) 2008 The American Phytopathological Society ing damage mainly in stone fruits when severe infection of blossoms occurs under warm and humid conditions (2). M. laxa is distributed in all major areas of stone and pome fruit production with a humid and moderate warm climate (4). A specialized form of this last species exists, M. laxa $\mathrm{f}$. sp. mali Harrison $\{$ ? , which is thought to be restricted to apple and causes blossom wilt, spur-kill, and canker. Few data on $M$. laxa f. sp. mali are available in the literature $(2,3)$. A severe blossom blight of apple was observed in apple orchards in India during 1983. The isolated pathogen was identified as $M$. laxa f. sp. mali $(30,31)$. The occurrence of M. laxa f. sp. mali in Slovenia was first reported in 1997, when an unusual dying of apple shoots was observed. During the blooming season of the next year, apple, apricot, and sour cherry trees were artificially inoculated with these apple isolates, and disease symptoms occurred only on apple trees, supporting the existence of the specialized form (5). In the following years, the disease spread throughout apple production areas in Slovenia.

Another species, M. mali (Takah.) Whetzel, autonomous and endemic to Japan and Russia, produces similar symptoms on apples as European M. laxa f. sp. mali $(2,3)$. In a survey of apple diseases in Korea, the authors found blossom blight caused by $M$. mali, a disease which had not occurred on apple since the mid-1970s (16). The infection mechanisms of $M$. mali are distinct from those described for $M$. laxa and $M$. fructigena, since the wilt appears before the blossoms open. M. mali can also be morphologically distinguished from the other three species based on the presence of disjunctors not present in the other three species from the Junctoriae group (2).

With the development of molecular tools, various genetic markers have become basic techniques for detecting, identifying, and classifying plant pathogenic fungi and are also very useful tools for evaluating genetic variability within or between species. Delineation of the three Monilinia species has been mainly achieved by analyzing certain parts of the genome, mainly for identification purposes: ITS and IGS regions (15), partial sequences of small DNA (ssrDNA), and large (lsrDNA) subunits of ribosomal DNA $(10,13)$. Information about the genetic structure and genetic diversity of Monilinia species is scarce. Based on the ITS nucleotide sequence, no variation was observed in isolates of $M$. laxa from Malus and Prunus spp. (13). On the basis of random amplified polymorphic DNA (RAPD) markers, variation in $M$. laxa exists but is randomly distributed worldwide (11). The first larger diversity study of M. laxa populations from peach, apricot, and almond orchards in Spain using the RAPD technique was recently reported (12).

Amplified fragment length polymorphism (AFLP) is a technique that combines the ease of finding polymorphic loci known for RFLP, with the economic applicability of polymerase chain reaction (PCR) and the possibility of controlling the number of fragments generated by primer extensions $(17,27)$. The efficiency of the AFLP technique for taxonomy, genetic diversity studies, and polymorphism assessment has been used in a number of biological systems $(9,25,32,34)$ to clarify closely related species that could not be resolved with morphological or other molecular systematic characters (18). Majer et al. (17) used AFLP fingerprinting for the first time for the detection of genetic polymorphism of two species of plant pathogenic fungi, Cladosporium fulvum and Pyrenopeziza brassicae.

The purposes of the current study were (i) to optimize the AFLP procedure for 
Table 1. Sixty-seven Monilinia laxa isolates used in the amplified fragment length polymorphism (AFLP) study, their host plants, geographical origin, year, and source of isolation

\begin{tabular}{|c|c|c|c|c|c|}
\hline No. & Isolate $^{\mathrm{a}}$ & Host plant & Origin $^{b}$ & Year & Source \\
\hline 12 & MLX0601 & Apricot (AP) & Ljubljana & 2006 & Young fruit \\
\hline 13 & MLX0602 & Apricot (AP) & Ljubljana & 2006 & Young fruit \\
\hline 21 & MLX0603 & Apricot (AP) & Ljubljana & 2006 & Young fruit \\
\hline 32 & MLX0605 & Apricot (AP) & Ljubljana & 2006 & Young fruit \\
\hline 40 & MLX0606 & Apricot (AP) & Vrtojba & 2006 & Young fruit \\
\hline 33 & MLX0607 & Apricot (AP) & Štanjel & 2006 & Young fruit \\
\hline 14 & MLX0610 & Sweet cherry $(\mathrm{CH})$ & Brdo pri Lukovici & 2006 & Young fruit \\
\hline 15 & MLX0611 & Sweet cherry $(\mathrm{CH})$ & Brdo pri Lukovici & 2006 & Young fruit \\
\hline 22 & MLX0612 & Sweet cherry $(\mathrm{CH})$ & Brdo pri Lukovici & 2006 & Young fruit \\
\hline 23 & MLX0614 & Sweet cherry $(\mathrm{CH})$ & Brdo pri Lukovici & 2006 & Young fruit \\
\hline 34 & MLX0615 & Sweet cherry $(\mathrm{CH})$ & Brdo pri Lukovici & 2006 & Young fruit \\
\hline 67 & MLX0616 & Sweet cherry $(\mathrm{CH})$ & Brdo pri Lukovici & 2006 & Young fruit \\
\hline 42 & MLX0618 & Sweet cherry $(\mathrm{CH})$ & Brdo pri Lukovici & 2006 & Mummified fruit \\
\hline 35 & MLX0619 & Sweet cherry $(\mathrm{CH})$ & Brdo pri Lukovici & 2006 & Young fruit \\
\hline 66 & MLX0621 & Sweet cherry $(\mathrm{CH})$ & Brdo pri Lukovici & 2006 & Young fruit \\
\hline 16 & MLX0623 & Apricot (AP) & Brdo pri Lukovici & 2006 & Blossom \\
\hline 17 & MLX0624 & Apricot (AP) & Brdo pri Lukovici & 2006 & Young fruit \\
\hline 18 & MLX0625 & Plum (PL) & Brdo pri Lukovici & 2006 & Young fruit \\
\hline 19 & MLX0628 & Peach (PE) & Brje pri Komnu & 2006 & Young fruit \\
\hline 20 & MLX0629 & Japanese quince (QUI) & Ljubljana & 2006 & Shoot \\
\hline 24 & MLX0630 & Japanese quince (QUI) & Ljubljana & 2006 & Young fruit \\
\hline 25 & MLX0631 & Apricot (AP) & Ptujska gora & 2006 & Young fruit \\
\hline 43 & MLX0633 & Sweet cherry $(\mathrm{CH})$ & Ptujska gora & 2006 & Young fruit \\
\hline 44 & MLX0634 & Sweet cherry $(\mathrm{CH})$ & Ptujska gora & 2006 & Young fruit \\
\hline 45 & MLX0635 & Sweet cherry $(\mathrm{CH})$ & Ptujska gora & 2006 & Young fruit \\
\hline 36 & MLX0637 & Japanese quince (QUI) & Ptujska gora & 2006 & Young fruit \\
\hline 47 & MLX0638 & Peach (PE) & Krško & 2006 & Young fruit \\
\hline 37 & MLX0646 & Apricot (AP) & Ljutomer & 2006 & Shoot \\
\hline 26 & MLX0652 & Japanese cherry (JCH) & Ljubljana & 2006 & Blossom peduncle \\
\hline 27 & MLX0653 & Japanese cherry (JCH) & Šmartno pod Šmarno goro & 2006 & Blossom peduncle \\
\hline 38 & MLX0654 & Japanese cherry (JCH) & Ljubljana & 2006 & Blossom peduncle \\
\hline 46 & MLX0655 & Japanese quince (QUI) & Kranj & 2006 & Blossom peduncle \\
\hline 48 & MLX0656 & Sweet cherry $(\mathrm{CH})$ & Horjul & 2006 & Blossom peduncle \\
\hline 28 & MLX0657 & Apple (APP) & Ljubljana & 2006 & Blossom peduncle \\
\hline 29 & MLX0658 & Apple (APP) & Ljubljana & 2006 & Blossom peduncle \\
\hline 30 & MLX0659 & Apple (APP) & Ljubljana & 2006 & Blossom peduncle \\
\hline 39 & MLX0660 & Apple (APP) & Ljubljana & 2006 & Blossom peduncle \\
\hline 49 & MLX0662 & Sweet cherry $(\mathrm{CH})$ & Ankaran & 2006 & Blossom peduncle \\
\hline 41 & MLX0663 & Sweet cherry $(\mathrm{CH})$ & Ankaran & 2006 & Blossom peduncle \\
\hline 50 & MLX0664 & Sweet cherry $(\mathrm{CH})$ & Ankaran & 2006 & Blossom peduncle \\
\hline 51 & MLX0665 & Apricot (AP) & Strunjan & 2006 & Blossom peduncle \\
\hline 52 & MLX0666 & Apricot (AP) & Strunjan & 2006 & Blossom peduncle \\
\hline 53 & MLX0667 & Apricot (AP) & Strunjan & 2006 & Blossom peduncle \\
\hline 54 & MLX0668 & Apricot (AP) & Strunjan & 2006 & Blossom peduncle \\
\hline 55 & MLX0670 & Sweet cherry $(\mathrm{CH})$ & Ljubljana & 2006 & Blossom peduncle \\
\hline 31 & MLX0675 & Apple (APP) & Resje & 2006 & Blossom peduncle \\
\hline 56 & MLX0677 & Apple (APP) & Resje & 2006 & Blossom peduncle \\
\hline 57 & MLX0678 & Apple (APP) & Resje & 2006 & Blossom peduncle \\
\hline 58 & MLX0679 & Apple (APP) & Resje & 2006 & Blossom peduncle \\
\hline 1 & MLX11KB & Apricot (AP) & Čentiba & 2004 & Twig \\
\hline 4 & MLX215P & Apple (APP) & Preddvor & 2003 & Young fruit \\
\hline 2 & MLX218K & Apricot (AP) & Maribor & 2003 & Twig \\
\hline 7 & MLX21K & Sweet cherry $(\mathrm{CH})$ & Pince & 2004 & Mummified fruit \\
\hline 5 & MLX3K & Apricot (AP) & Pijava Gorica & 2004 & Twig \\
\hline 8 & MLX53P & Apple (APP) & Škofja Loka & 2004 & Twig \\
\hline 9 & MLX63P & Apple (APP) & Zgornja Polskava & 2004 & Twig \\
\hline 10 & MLX64P & Apple (APP) & Cerklje ob Krki & 2004 & Twig \\
\hline 11 & MLX65P & Apple (APP) & Sevnica & 2004 & Twig \\
\hline 3 & MLX67P & Apple (APP) & Pečarovci & 2004 & Twig \\
\hline 6 & MLX71K & Plum (PL) & Rodež & 2004 & Mature fruit \\
\hline 59 & $2809 \mathrm{G}$ & Unknown (UNK) & Japan & n.a. & n.a. \\
\hline 60 & 7809D & Unknown (UNK) & Japan & n.a. & n.a. \\
\hline 61 & $1888 \mathrm{D}$ & Unknown (UNK) & Japan & n.a. & n.a. \\
\hline 62 & $1888 \mathrm{G}$ & Unknown (UNK) & Japan & n.a. & n.a. \\
\hline 63 & CBS298.31 & Malus sylvestris (MSYL) & Ireland & 1931 & Twig \\
\hline 64 & CBS101505 & Prunus mите (PMU) & Japan & 1989 & n.a. \\
\hline 65 & CBS101507 & Apricot (AP) & Australia & 1978 & n.a. \\
\hline
\end{tabular}

${ }^{a}$ Isolates 1 to 11 were obtained from the Agricultural Institute of Slovenia, Plant Protection Department, Ljubljana; isolates 59 to 62 were a gift from Kazuaki Tanaka, Laboratory of Phytopathology of the Faculty of Agriculture and Life Science, Hirosaki University; and isolates 63 to 65 were obtained from CBS, Utrecht, The Netherlands.

${ }^{\mathrm{b}}$ Isolates except 59 to 65 are from Slovenia, their collection sites are presented in Figure 1. 
M. laxa; (ii) to ascertain the usefulness of a multilocus marker system for studying genetic variability and to capture the population structure present within the species of M. laxa isolates from different hosts; and (iii) to study relationship and diversity among fungal isolates from different hosts. Here we report the results of AFLP analysis of 67 M. laxa isolates screened with 20 different AFLP primer combinations.

\section{MATERIALS AND METHODS}

Fungal isolates and culture conditions. In total, 67 single-spore isolates of $M$. laxa were included in our research (Table 1). The isolates were collected from a wide range of hosts comprising pome and stone fruits from different collection sites in Slovenia (Fig. 1, 60 isolates): 18 isolates from sweet cherry $(\mathrm{CH})$ (Prunus avium), 17 from apricot (AP) (Prunus armeniaca), 14 from apple (APP) (Malus domestica), 4 from Japanese quince (QUI) (Cydonia oblonga), 3 from Japanese cherry (JCH) (Prunus serrulata), 2 from peach (PE) (Prunus persica), and 2 from plum (PL) (Prunus domestica). The remaining 7 isolates were acquired abroad: 4 isolates $(2809 \mathrm{G}, 7809 \mathrm{D}, 1888 \mathrm{D}$, and
1888G) of $M$. laxa isolated from unknown host plant were from Japan (Laboratory of Phytopathology of Faculty of Agriculture and Life Science, Hirosaki University, Kazuaki Tanaka), and 3 reference isolates from Ireland (apple), Japan (Japanese apricot: Prunus mume), and Australia (apricot) (CBS 298.31, CBS 101505, and CBS 101507) were obtained from the Centraalbureau voor Schimmelcultures (CBS) culture collection in Utrecht, the Netherlands.

All collected isolates were cultured from sporodochia that had developed on different parts of infected host tissue. They were identified on the basis of morphological traits and also with molecular diagnostic assay using species-specific primers according to the described methods $(14,15)$ (data not shown). Isolates were maintained on potato dextrose agar (PDA) medium (5 $\mathrm{g}$ of potato extract, $20 \mathrm{~g}$ of glucose, and 14 $\mathrm{g}$ of agar per liter) (Biolife, Italiana) in petri dishes in the dark at 18 to $22^{\circ} \mathrm{C}$. For long-term storage, fungi were grown on PDA slants at $4^{\circ} \mathrm{C}$ and fungal plugs from petri dishes were also stored in glycerol at $-80^{\circ} \mathrm{C}$.

Fungal culture and DNA isolation. Liquid fungal cultures were initiated by inoculating $150 \mathrm{ml}$ of malt extract broth (17 g/liter) (Merck KGgA, Darmstadt, Germany) in Erlenmeyer flasks with three 4-mm-diameter fungal plugs from PDA medium. They were incubated at $25^{\circ} \mathrm{C}$, $100 \mathrm{rpm}$, for 5 days. Mycelia were harvested by vacuum filtering through Whatman filter paper and washed twice with sterile distilled water.

DNA was extracted from $0.5 \mathrm{~g}$ of fungal mycelium wrapped in foil to avoid losing the tissue during grinding with liquid nitrogen in a mortar. One milliliter of warm $\left(68^{\circ} \mathrm{C}\right) \mathrm{CTAB}$ extraction buffer was added to the ground mycelium $(2 \% \quad[\mathrm{wt} / \mathrm{vol}]$ CTAB, $100 \mathrm{mM}$ Tris- $\mathrm{HCl}, \mathrm{pH} 8,20 \mathrm{mM}$ EDTA, $\mathrm{pH} 8,1.4 \mathrm{M} \mathrm{NaCl}$, and $0.2 \%$ [vol/vol] $\beta$-mercaptoethanol) and incubated at $68^{\circ} \mathrm{C}$ for $2 \mathrm{~h}$. After incubation, phenol:chloroform:isoamyl alcohol (25:24:1) extraction was performed. The emulsion was centrifuged for $15 \mathrm{~min}$ and the DNAcontaining aqueous phase was again extracted with chloroform:isoamyl alcohol (24:1). DNA was precipitated with sodium acetate (3 M, pH 5.2) and ice-cold isopropanol. DNA was pelleted by centrifugation, rinsed with $70 \%$ ethanol, and resuspended in $30 \mu \mathrm{l}$ of TE buffer (10 mM Tris-

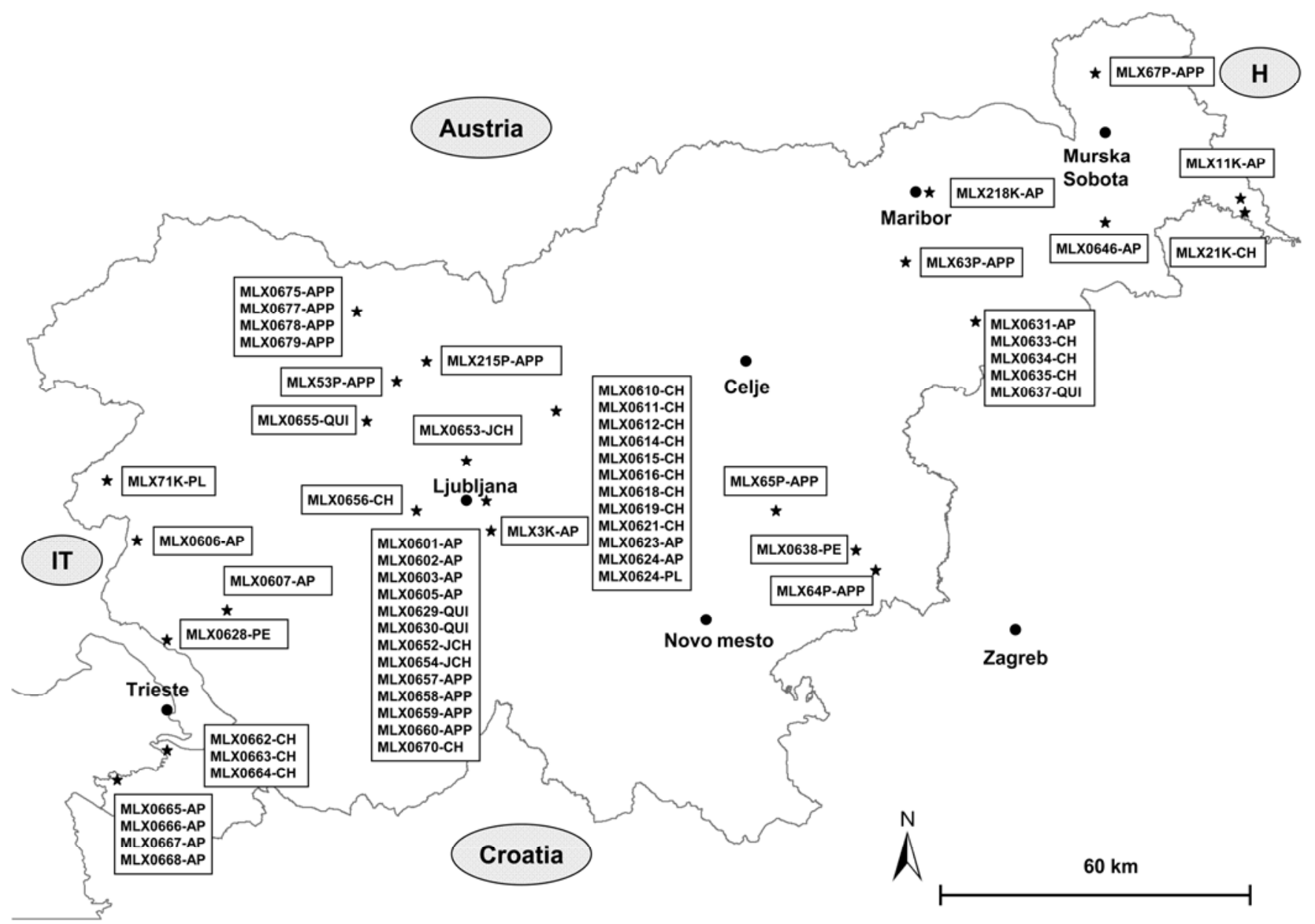

Fig. 1. Map of collection sites of 60 Slovenian Monilinia laxa isolates (marked with asterisks) from different host plants. Names correspond to the names in Table 1. Host plants are marked with abbreviations after the isolate name: AP, apricot; APP, apple; CH, sweet cherry; JCH, Japanese cherry; PE, peach; PL, plum; and QUI, Japanese quince. In addition to Slovenian isolates, 4 Japanese isolates from unknown plants and 3 reference (CBS) $M$. laxa isolates were obtained: 2809G, 7809D, 1888D, 1888G, CBS298.31 (Malus sylvestris, Ireland), CBS101505 (Prunus mume, Japan), and CBS101507 (apricot, Australia). 
$\mathrm{HCl}, \mathrm{pH}$ 8.0, 1 M EDTA, pH 8.0). The extracted DNA was stored at $-20^{\circ} \mathrm{C}$ until further use. Extracted DNA was electrophoresed on $0.8 \%$ agarose gel and stained with ethidium bromide $(0.5 \mu \mathrm{g} / \mathrm{ml})$ for quality control. DNA concentration was quantified by fluorimetry (Amersham Biosciences DynaQuant 200).

AFLP analysis. AFLP reactions were performed as originally described (37) with minor modifications including exchanging $M s e$ I AT rich recognizing restriction enzyme for GC rich $M s p$ I restriction enzyme (23).

Two hundred and fifty nanograms of fungal genomic DNA was digested with restriction enzymes EcoRI and MspI (2.5 $\mathrm{U}$ of each enzyme, New England Biolabs) in a reaction volume of $40 \mu \mathrm{l}$ at $37^{\circ} \mathrm{C}$ for 3 h. After digestion, $5 \mathrm{pmol}$ of Eco and 50 pmol of Msp double-stranded adaptors were ligated (1 Weiss U of T4 DNA ligase) to the sticky ends of the genomic fragments in a final volume of $50 \mu \mathrm{l}$ at $37^{\circ} \mathrm{C}$ for $3 \mathrm{~h}$. Adaptors were obtained by mixing equimolar amounts of primers EcoRI linker1 (5' CTCGTAGACTGCGTACC 3') and EcoRI linker2 (5' AATTGGTACG CAGTCTAC $3^{\prime}$ ) for Eco adapters and MspI linker1 (5' GACGATGAGTCC TGAG $3^{\prime}$ ) and $M s p$ I linker2 (5' CGC TCAGGACTCAT $3^{\prime}$ ) for $M s p$ adapters.

Five microliters of ligation reaction served as a template in the PCR preamplification step in a $50-\mu l$ volume with the following components: onefold PCR buffer, $1.5 \mathrm{mM} \mathrm{MgCl}_{2}, 0.2 \mathrm{mM}$ of each dNTP, $75 \mathrm{ng}$ of EcoRI and MspI preamplification primers without any selective nucleotide (EcoRI+0: 5' GACTGCGTAC CAATTC+0 $3^{\prime}$ and MspI+0: 5' GAT GAGTCCTGAGCGG+0 $3^{\prime}$ ), and $1 \mathrm{U}$ of Taq DNA polymerase. Reactions were amplified in a GeneAmp PCR System 9700 (Perkin Elmer) repeating 20 cycles of $94^{\circ} \mathrm{C}$ for $30 \mathrm{~s}, 56^{\circ} \mathrm{C}$ for $1 \mathrm{~min}$, and $72^{\circ} \mathrm{C}$ for $1 \mathrm{~min}$.

The PCR products from the preamplification step were diluted 10-fold, and $2 \mu \mathrm{l}$ of the dilution was used for selective amplification, using the same core primers as in the first amplification with an additional two arbitrary (selective) nucleotides at the $3^{\prime}$ end. Selective reactions were performed in $10 \mu \mathrm{l}$ of PCR reaction mix with the same reaction components as for the preamplification step, except that $0.3 \mathrm{U}$ of $\mathrm{Taq}$ polymerase was used and $50 \mathrm{ng}$ of each selective primer, whereby EcoRI primers were Cy5 labeled at their $5^{\prime}$ end to allow automated laser fluorescence analysis. The reaction was amplified with an initial touch down protocol: $94^{\circ} \mathrm{C}$ for $30 \mathrm{~s}, 65^{\circ} \mathrm{C}$ for $30 \mathrm{~s}$, and $72^{\circ} \mathrm{C}$ for $1 \mathrm{~min}$ for 12 cycles, in each cycle the annealing temperature was decreased by $0.7^{\circ} \mathrm{C}$, followed by 23 cycles: $94^{\circ} \mathrm{C} 30 \mathrm{~s}, 56^{\circ} \mathrm{C} 30 \mathrm{~s}$, and $72^{\circ} \mathrm{C} 1$ min. Based on initial screening of 40 different primer combinations on 4 different fungal isolates, 20 primer combinations were chosen (combinations of 4 EcoRI [E] and $10 \mathrm{MspI}[\mathrm{M}]$ primers) based on amplification profile intensity, number of amplified bands, and indicative polymorphism. The combinations of primers used for amplification were as follows: $\mathrm{E}-\mathrm{AC}$ in combination with M-TA, M-GT, M-TC, M-CT, M-TG, and M-AG; E-GA in combination with M-CG, M-CT, M-AT, M-TA, M-AG, M-TC, and M-GT; E-GT in combination with M-CG, M-GA, and M-GC; and E-TC

Table 2. Characteristics of amplified fragment length polymorphism (AFLP) markers generated by 20 primer combinations in analysis of 67 Monilinia laxa isolates

\begin{tabular}{|c|c|c|c|c|c|c|c|c|c|c|c|}
\hline \multirow[b]{2}{*}{ Comb. } & \multicolumn{2}{|c|}{ Primer pair } & \multirow{2}{*}{$\begin{array}{l}\text { No. of all } \\
\text { fragments }\end{array}$} & \multirow{2}{*}{$\begin{array}{c}\text { Fragment } \\
\text { length }\end{array}$} & \multirow{2}{*}{$\begin{array}{c}\text { No. of } \\
\text { polymorphic } \\
\text { fragments }\end{array}$} & \multirow{2}{*}{$\begin{array}{c}\% \\
\text { Polymorphism }\end{array}$} & \multirow{2}{*}{$\begin{array}{c}\text { No. of } \\
\text { fragments } \\
\text { per isolate } \\
\text { (min; max) }\end{array}$} & \multirow{2}{*}{$\begin{array}{c}\text { No. of } \\
\text { polymorphic } \\
\text { fragments } \\
\text { per isolate } \\
\text { (min; max) }\end{array}$} & \multirow{2}{*}{$\begin{array}{c}\text { No. of } \\
\text { unique } \\
\text { fragments } \\
\text { in one } \\
\text { isolate }\end{array}$} & \multirow{2}{*}{$\begin{array}{c}\text { No. of } \\
\text { unique } \\
\text { fragments } \\
\text { in apple } \\
\text { isolates }\end{array}$} & \multirow{2}{*}{$\begin{array}{c}\text { No. of } \\
\text { unique } \\
\text { fragment } \\
\text { in other } \\
\text { isolates }\end{array}$} \\
\hline & E- & M- & & & & & & & & & \\
\hline 1 & $\mathrm{AC}$ & TA & 58 & $55-695$ & 28 & 48.28 & $36 ; 46$ & $6 ; 16$ & 4 & 4 & 3 \\
\hline 2 & $\mathrm{AC}$ & GT & 57 & $65-725$ & 24 & 42.11 & $33 ; 52$ & $1 ; 9$ & 4 & 1 & 2 \\
\hline 3 & $\mathrm{AC}$ & $\mathrm{TC}$ & 46 & $59-607$ & 22 & 47.83 & $33 ; 39$ & $9 ; 15$ & 2 & 1 & 1 \\
\hline 4 & $\mathrm{AC}$ & CT & 56 & $50-568$ & 18 & 32.14 & $41 ; 51$ & $3 ; 13$ & 2 & 0 & 0 \\
\hline 5 & AC & TG & 59 & $50-636$ & 22 & 37.29 & $39 ; 47$ & $2 ; 10$ & 4 & 1 & 0 \\
\hline 6 & $\mathrm{AC}$ & $\mathrm{AG}$ & 55 & $50-717$ & 21 & 38.18 & $40 ; 49$ & $6 ; 15$ & 2 & 1 & 0 \\
\hline 7 & GA & CG & 58 & $71-525$ & 18 & 31.03 & $44 ; 52$ & $4 ; 12$ & 5 & 1 & 0 \\
\hline 8 & GA & CT & 49 & $74-484$ & 27 & 55.10 & $21 ; 42$ & $4 ; 20$ & 2 & 1 & 0 \\
\hline 9 & GA & AT & 96 & $50-524$ & 29 & 30.21 & $36 ; 94$ & $5 ; 16$ & 5 & 1 & 2 \\
\hline 10 & GA & TA & 69 & $50-340$ & 22 & 31.88 & $51 ; 63$ & $6 ; 16$ & 0 & 0 & 0 \\
\hline 11 & GA & AG & 70 & $50-607$ & 18 & 25.71 & $58 ; 63$ & $6 ; 11$ & 1 & 3 & 1 \\
\hline 12 & GA & $\mathrm{TC}$ & 52 & $60-565$ & 17 & 32.69 & $37 ; 49$ & $2 ; 14$ & 0 & 1 & 1 \\
\hline 13 & GA & GT & 71 & $80-745$ & 16 & 22.54 & $56 ; 63$ & $1 ; 8$ & 2 & 0 & 0 \\
\hline 14 & GT & CG & 33 & $50-476$ & 4 & 12.12 & $29 ; 33$ & $0 ; 4$ & 0 & 1 & 0 \\
\hline 15 & GT & GA & 33 & $69-483$ & 11 & 33.33 & $24 ; 29$ & $2 ; 7$ & 0 & 1 & 1 \\
\hline 16 & GT & GC & 35 & $50-534$ & 5 & 14.29 & $31 ; 35$ & $1 ; 5$ & 0 & 0 & 0 \\
\hline 17 & $\mathrm{TC}$ & TA & 45 & $50-494$ & 15 & 33.33 & $35 ; 42$ & $5 ; 12$ & 0 & 1 & 0 \\
\hline 18 & $\mathrm{TC}$ & GA & 50 & $50-447$ & 6 & 12.00 & $27 ; 49$ & $0 ; 5$ & 0 & 0 & 0 \\
\hline 19 & $\mathrm{TC}$ & $\mathrm{AG}$ & 59 & $50-557$ & 24 & 40.68 & $44 ; 55$ & $9 ; 20$ & 0 & 5 & 1 \\
\hline 20 & $\mathrm{TC}$ & CG & 38 & $50-428$ & 7 & 18.42 & $33 ; 38$ & $2 ; 7$ & 0 & 0 & 0 \\
\hline Sum & & & 1,089 & & 354 & & & & 33 & 23 & 12 \\
\hline Average & & & 54.5 & & 17.7 & 32.51 & $37.4 ; 51.8$ & $3.7 ; 11.8$ & & & \\
\hline
\end{tabular}

Table 3. Analysis of molecular variance (AMOVA) of 354 polymorphic amplified fragment length polymorphism (AFLP) loci among 67 isolates of Monilinia laxa

\begin{tabular}{lrccc}
\hline Source of variation & df & $\begin{array}{c}\text { Variance } \\
\text { components }\end{array}$ & $\begin{array}{c}\text { Percentage of } \\
\text { total variation }\end{array}$ & $\begin{array}{c}\boldsymbol{\Phi} \text {-statistics } \\
\boldsymbol{P}\end{array}$ \\
\hline Among isolates from different hosts A (apple vs. all other) & 1 & 0.08802 & 47.50 & 0.47496 \\
Within groups of isolates & 65 & 0.09730 & 52.50 & $<0.0001$ \\
Among isolates from different hosts B (apple vs. apricot) & 1 & 0.08550 & 44.24 & 0.44238 \\
Within groups of isolates & 31 & 0.10778 & 55.76 & $<0.0001$ \\
Among isolates from different hosts C (apple vs. sweet cherry) & 1 & 0.08962 & 47.03 & 0.47028 \\
Within groups of isolates & 31 & 0.10094 & 52.97 & $<0.0001$ \\
Among isolates from different hosts D (sweet cherry vs. apricot) & 1 & 0.00015 & 0.17 & 0.00167 \\
Within groups of isolates & 34 & 0.09255 & 99.83 & 0.3529 \\
\hline
\end{tabular}


in combination with M-TA, M-GA, M-AG, and M-CG (Table 2). The amplification reaction was mixed with an equal volume $(10 \mu \mathrm{l})$ of formamide loading buffer $(5 \mathrm{mg}$ dextrane blue in $1 \mathrm{ml}$ of formamide), denaturated by heating to $94^{\circ} \mathrm{C}$ for $4 \mathrm{~min}$, and the samples were immediately transferred onto ice. Five microliters of sample was

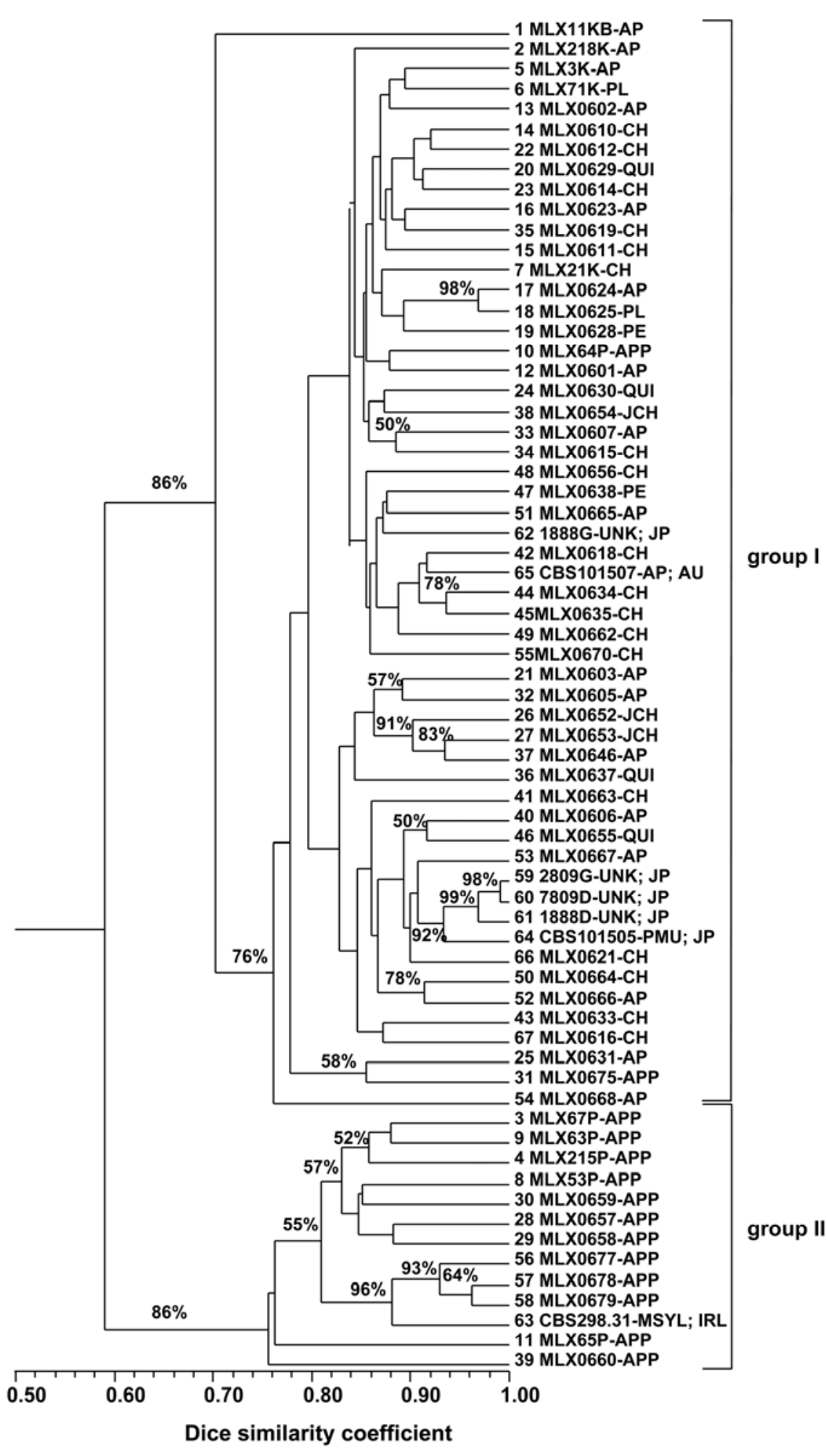

Fig. 2. Unweighted pair group method using arithmetic averages (UPGMA) dendrogram based on 67 Monilinia laxa isolates and 354 amplified fragment length polymorphism (AFLP) polymorphic loci used to calculate Dice's coefficient of similarity. Numbers at nodes denote bootstrap values for 1,000 replicates, only values greater than or equal to $50 \%$ are shown. Numbers before isolate names are numbers from Table 1, abbreviation after isolate name denotes host plant: AP, apricot; APP, apple; $\mathrm{CH}$, sweet cherry; JCH, Japanese cherry; PE, peach; PL, plum; QUI, Japanese quince; PMU, Prunus mume; MSYL, Malus sylvestris; and UNK, unknown. Foreign isolates are also marked with country name: AU, Australia; JP, Japan; and IRL, Ireland. In group II, only isolates from apple trees are present, while isolates from all other host plants are placed in group I. loaded onto $5 \%$ polyacrylamide denaturating gel $(5 \%$ acrylamide-bisacrylamide 19:1, 1× TBE, $7 \mathrm{M}$ urea) and electrophoresed on an ALFexpressII (Amersham Biosciences) sequencer at limiting power $15 \mathrm{~W}$ and constant temperature $55^{\circ} \mathrm{C}$ for 300 min. An external size standard ranging from 50 to $500 \mathrm{bp}$ was run together with samples to allow further sizing of the fragments.

Band scoring and genetic data analysis. Allele Locator 1.03 (Amersham Biosciences) program was used for gel analysis. Fragments were sized against a 50- to 500-bp molecular standard, and fragments of the same size present in all isolates were used to correct for smiling effect of the gels.

Only strong and reliably amplified markers were scored as binary variables, either with presence (1) or absence (0). Monomorphic markers were excluded from further diversity assessment. The genetic similarity among isolates was calculated using Dice's similarity index (21). Cluster analysis was generated from the similarity matrix by the unweighted pair group method using the arithmetic averages (UPGMA) algorithm, with the "FIND" option enabled to detect all possible trees. The goodness of fit of the clustering to the data matrix was estimated by the COPH and MXCOPM subprograms of NTSYS, which calculate cophenetic values and perform matrix comparison analysis, respectively. All calculations were performed by the computer program NTSYSpc 2.02 (26). Branch support was performed by bootstrap analysis of 1,000 bootstrap replicates by the TreeCon program (36). Additionally, a principal coordinate analysis (PCO) based on Dice's similarity data matrix was also carried out, using NTSYS-pc program modules DCENTER, EIGEN, and MXPLOT to generate two-dimensional presentation.

Model-based clustering employing a Bayesian algorithm was applied to infer the genetic structure of the analyzed $M$. laxa isolates using Structure software (22). Ten independent runs of the program were performed by setting the number of clusters $(\mathrm{K})$ from 1 to 10 ; each run consisted of a burn-in period of 10,000 iterations followed by $10^{5}$ MCMC (Monte Carlo Markov Chain) iterations, assuming an admixture model and correlated allele frequencies. For other settings, program defaults were used and no prior information was used to define the clusters. The most likely number of clusters (K) was chosen, based on the logarithmized probabilities of data $\operatorname{Pr}(\mathrm{X} \mid \mathrm{K})$ for each value of clusters (K) and by ad hoc statistic $\Delta K(7)$.

An analysis of molecular variance (AMOVA) analysis was carried out using Arlequin software (29) to statistically test the existence of different groups within the species. Several groups of isolates were defined for testing the probable host spe- 
cialization: (i) apple isolates (15 samples) and all other isolates (52 samples), (ii) apple isolates and sweet cherry isolates (18 samples), and (iii) apple isolates and apricot isolates (18 samples) (Table 1); and four different AMOVA tests were conducted (apple versus all other, apple versus apricot, apple versus sweet cherry, and sweet cherry versus apricot). The significance level for AMOVA calculations was 0.01 (Table 3).

\section{RESULTS}

AFLP analysis. Four isolates from different host plants (2 from apple, 1 apricot, and 1 sweet cherry) were initially analyzed for amplification pattern and tentative level of polymorphism for all 40 possible primer combinations with four different EcoRI primers (E-TC, E-AC, E-GA, and E-GT) and $10 \mathrm{MspI}$ primers (M-CT, M-TA, MGC, M-GA, M-TG, M-AG, M-TC, M-CG, $\mathrm{M}-\mathrm{AT}$, and M-GT). The unambiguity of the banding pattern, the total number of amplified markers, and the length range of amplified fragments were the main criteria for choosing particular primer combinations. Finally, 20 primer combinations (Table 2) were selected to screen genetic diversity in the whole sample of 67 isolates.

AFLP analysis of 67 different $M$. laxa isolates yielded a total of 1,089 wellspaced fragments from 20 chosen primer combinations. All bands were reproducible when fingerprints were repeated. The highest number of fragments (96) was amplified with primer combination EGA+M-AT, while the fewest bands (33) were scored in two E-GT primer combinations with different $\mathrm{M}$-selective nucleotides (M-CG, M-GA). On average, there were 54.5 AFLP markers per primer combination in the range from 50 to $745 \mathrm{bp}$. The highest number of polymorphic fragments (29) was detected by primer combination $\mathrm{E}-\mathrm{GA}+\mathrm{M}-\mathrm{AT}$, while primer pair EGT+M-CG produced the fewest polymorphic bands (4) in the analyzed group of 67 isolates. The average percentage of polymorphism ranged from $12 \%$ for the primer combination E-TC+M-GA to $55.1 \%$ for the E-GA+M-CT combination. The main AFLP characteristics for 20 primer combinations are presented in Table 2.

Polymorphisms are noticed between isolates with an average of 17.7 polymorphic bands per primer pair. Consequently, we considered 354 polymorphic bands $(32.5 \%$ of the total bands) for further analysis. On average, between 37.4 and 51.8 AFLP fragments per isolate were obtained (min, $\max$ ), and between 3.7 and 11.8 polymorphic AFLP markers per isolate were scored (min, max) (Table 2).

Specific markers present only in one isolate, or within the fingerprints of the isolates grouped according to host, were discovered (apple versus all other isolates). For example, 23 fragments in size from 62 to 583 bp were detected exclusively in fingerprints of isolates from apple; the highest number of unique fragments, 5, was detected in primer combination ETC+M-AG. Six primer combinations did not amplify any of the specific markers in apple isolates. Fewer, 12 unique markers, were also observed in the group of isolates from other host plants in length between 55 and $576 \mathrm{bp}$. The highest number, 6, was amplified with E-AC primers (3 with MTA, 2 with M-GT, and 1 with M-TC). Only 4 fragments with E-GA (2 with M-AT, 1 with M-AG, 1 with M-TC) and 1 specific marker were amplified in two combinations (E-GT+M-GA and E-TC+M-AG).

Genetic distance analysis. Dice's similarity coefficient (21) averaged among all cultivars was 0.743 . The highest similarity coefficient, 0.99, was between Japanese isolates 2809G (\#59) and 7809D (\#60), and the lowest, 0.434, was between an apricot (MLX11KB, \#1) and an apple (MLX0660, \#39) isolate.

Clustering analysis based on Dice's similarity coefficient and UPGMA clustering revealed two well-supported groups of isolates (Fig. 2). The larger group (group I) consisted of 54 isolates from stone fruits, quince, and 2 apple isolates (MLX64P, \#10; and MLX0675, \#31), and they clustered together at a bootstrap value of $86 \%$. A second group (group II) contained 13 out of 15 isolates obtained from infected apple trees. High variability of isolates can be seen within the two clusters, but isolates were not further clustered based on host species or geographical origin, with the exception of clustering of four Japanese isolates (2809G, \#59; 7809D, \#60; 1888D, \#61; and CBS101505, \#64). Clustering results were confirmed with a high cophenetic correlation $(r=0.94)$ and by bootstrap values of some clusters.

Principal coordinate analysis (PCO) of the AFLP-based distance data was performed to provide additional differentiation. The first and second principal coordinates explained $29.6 \%$ and $11.1 \%$ of the total variation, respectively (Fig. 3). Similar to the UPGMA cluster analysis, the two-dimensional plot resulting from PCO separated the studied isolates into two main groups according to the origin of host plants, group I (right side of the figure, all nonapple isolates) and group II (left side of the figure, apple isolates). Two apple isolates (MLX0675, \#31; and MLX65P, \#11) did not cluster to either of the main groups. The first isolate was placed in the UPGMA dendrogram in group I, while isolate MLX65P (\#11) still belonged to group II. The PCO figure placed apple isolate MLX64P (\#10) in group I, as in the UPGMA dendrogram. Two apple isolates, one from Ireland (CBS298.31, \#63) and one from Slovenia (MLX0660, \#39) were placed slightly away from the primary apple isolates distribution. No other grouping related to the geographic or host origin was observed in the part of the PCO figure in which group I isolates were placed.

An alternative model-based method for inferring the number of different clusters of individuals without predefined structure within 67 isolates was also employed (22). The method also confirmed a clear separation of the two groups of isolates and sup-

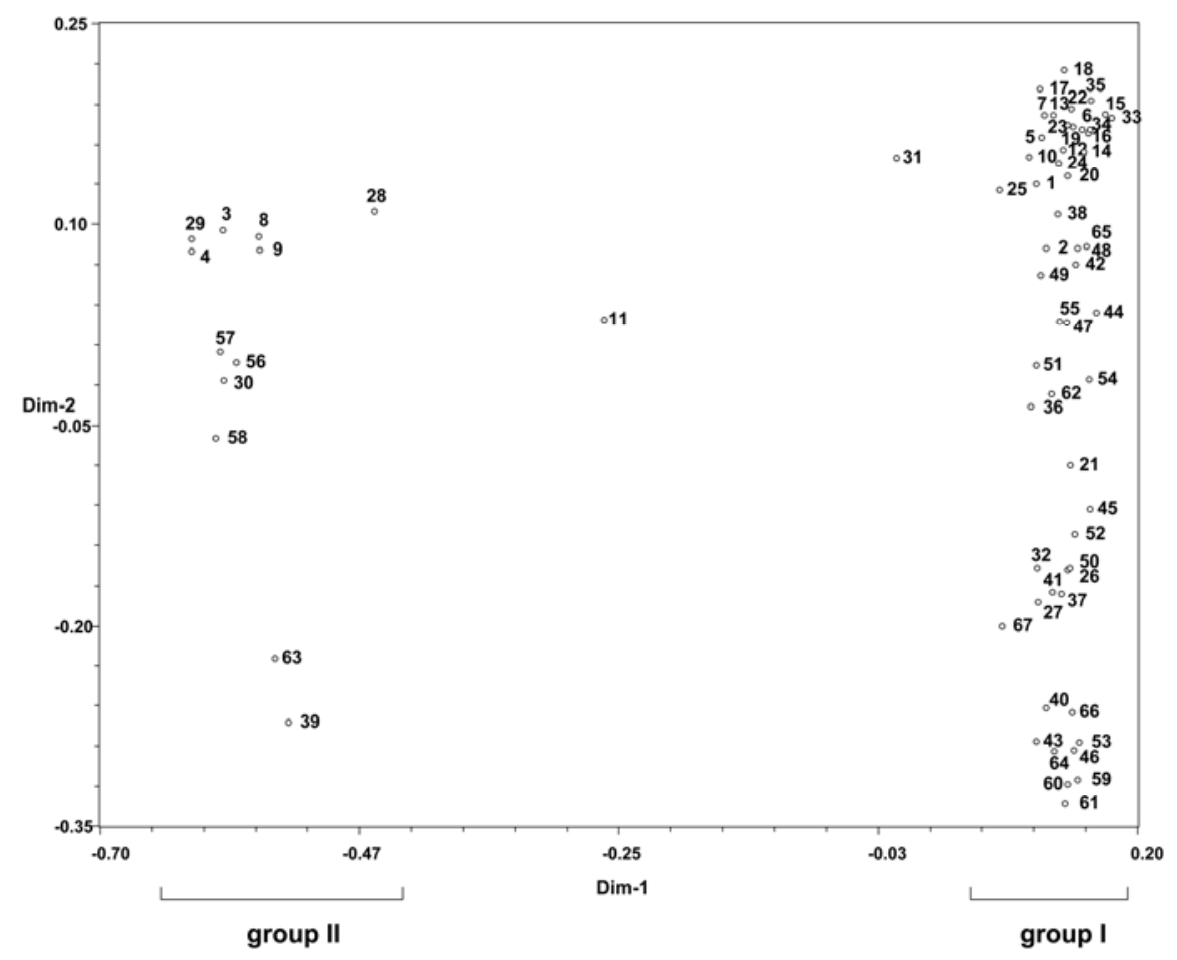

Fig. 3. Principal coordinate analysis (PCO) among 67 Monilinia laxa isolates based on their Dice's genetic distances. 
ported the existence of two clusters (group I and II) in the analyzed M. laxa isolates, in terms of host specific origin. The highest value of the estimated log probability of data $\operatorname{Pr}(\mathrm{X} \mid \mathrm{K})$ did not indicate the number of clusters (Fig. 4A), but the results of ad hoc statistic $\Delta \mathrm{K}(7)$ clearly arranged the

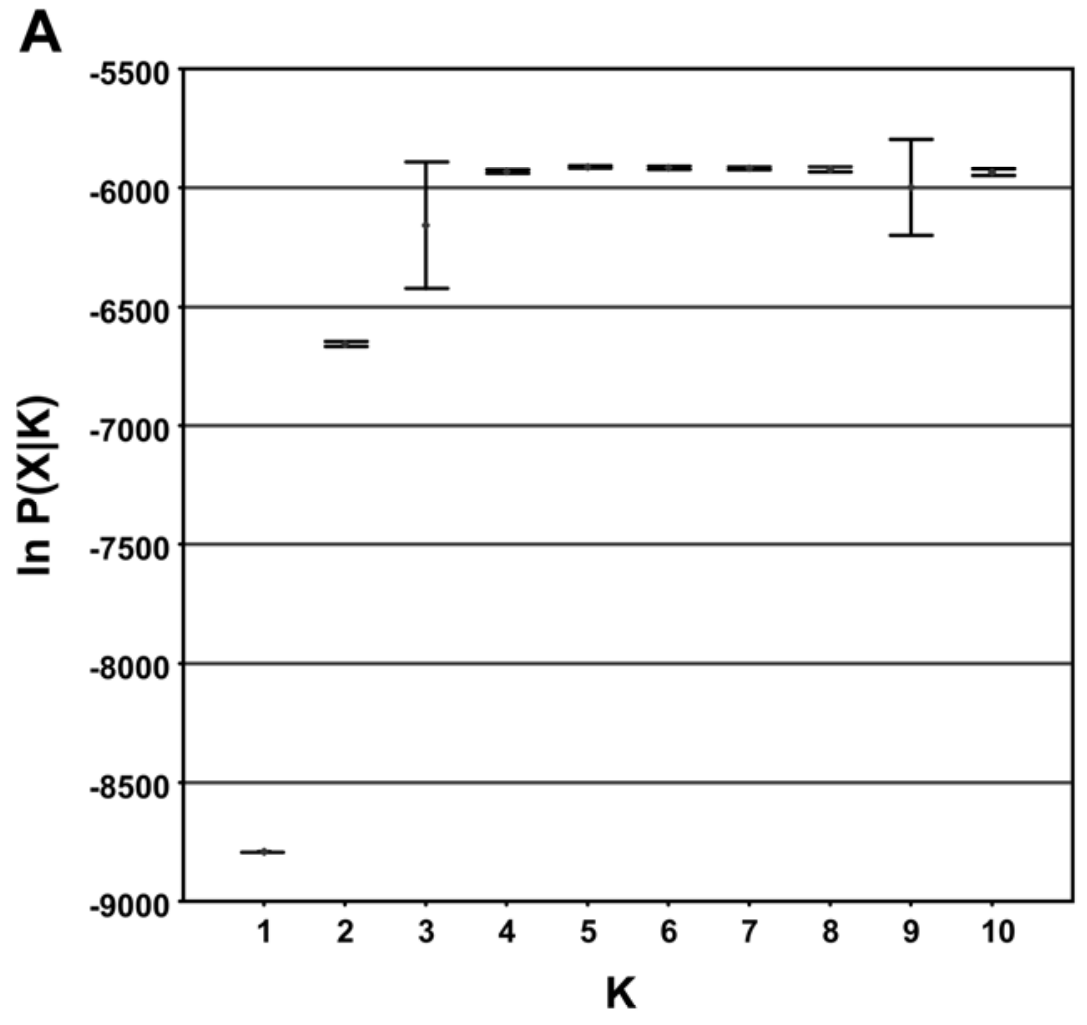

B

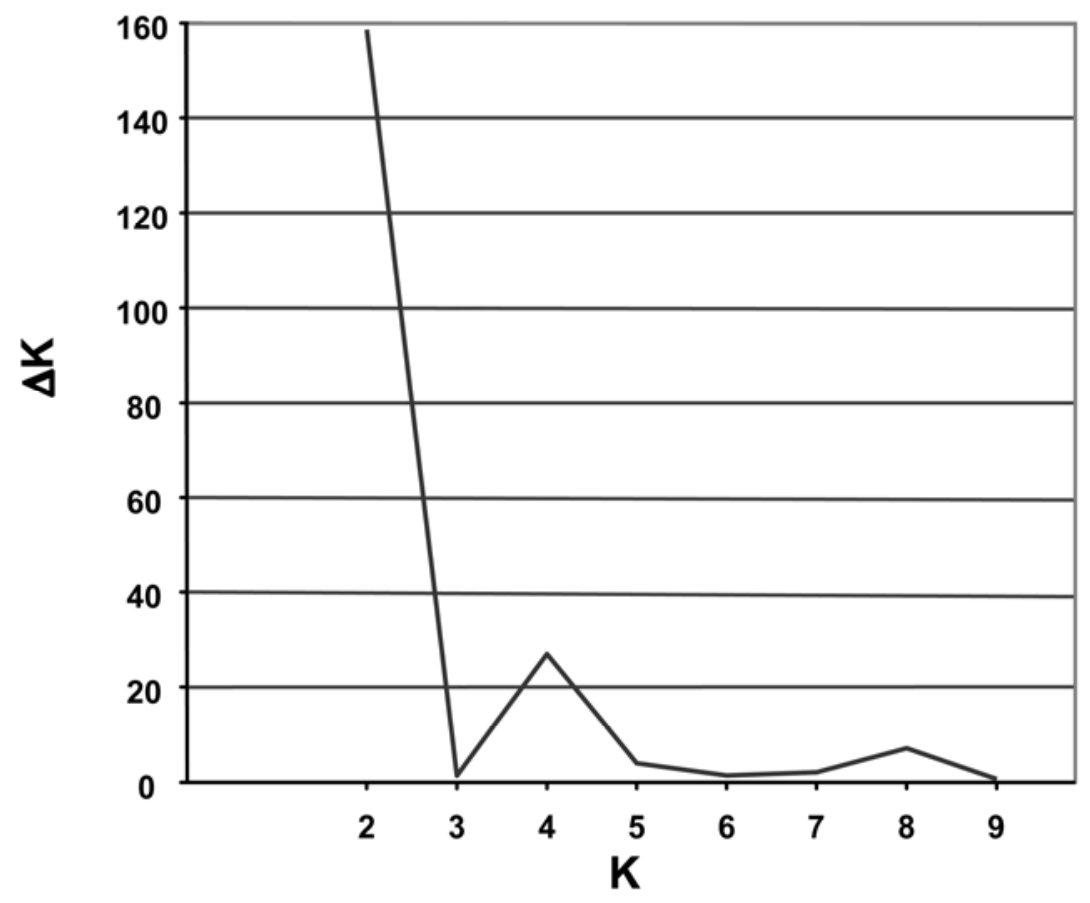

Fig. 4. The choice of the most likely number of clusters $(K)$ : $\mathbf{A}$, plot of mean $\ln \mathrm{P}(\mathrm{X} \mid \mathrm{K})$ values $( \pm \mathrm{SD})$ over 10 independent runs for each $\mathrm{K}(\mathrm{K}=1$ to 10$)$; $\mathbf{B}$, plot of $\Delta \mathrm{K}$ values for each $\mathrm{K}$ based on the second order rate of change of the likelihood function with respect to $\mathrm{K}$ reveals two groups of isolates. isolates into two groups (group I and group II) (Fig. 4B) composed of 65 isolates, as observed in UPGMA and PCO analysis. Two isolates from apple (MLX64P, \#10; and MLX0675, \#31) were not assigned as group II isolates, supporting UPGMA and the PCO analysis.

formed separately for four different groups of isolates grouped according to host origin. In three cases, AMOVA resulted in highly significant $(P<0.0001)$ differences between apple isolates and groups of all other isolates, apricot isolates, and sweet cherry isolates, which was not the case for the AMOVA results between sweet cherry and apricot isolates (Table 3 ). The variance among isolates for the first three groups (A, B, and C; Table 3) accounted for a slightly higher percentage of the total variance $(52.5$ to $55.7 \%)$ than the variance among the groups (44 to 47\%). For the last group compared (sweet cherry and apricot isolates, D; Table 3), the variance component among the groups contributed only $0.17 \%$ of the total variance, indicating the absence of genetic differentiation at this level and no indicative host specialization.

\section{DISCUSSION}

This is the first report of the use of AFLP techniques in diversity analysis of $M$. laxa isolates from different hosts. The AFLP technique can be regarded as a marker system of choice for revealing genetic diversity in closely related and morphologically similar plant pathogenic fungi and has been successfully applied as an effective taxonomy tool among different Fusarium (19,28), Verticillium (8), and Botrytis (33) species.

Twenty different AFLP primer combinations (Table 2) amplified on an average 54.5 fragments per combination, which is similar to reports on Fusarium sp. (6) and V. albo-atrum (24) isolates (51 and 42.8 fragments, respectively) but distinct from B. tulipae isolates (14.6 fragments) (33).

UPGMA and PCO clustering, AMOVA analysis, and a model-based clustering method clearly differentiated 13 out of 15 apple isolates from all other isolates (groups I and II), while isolates from other host plants did not show differentiation. This is the first report that M. laxa isolates from infected apple trees are distinguished from other host isolates by genetic polymorphisms and supports the biological specialization of apple isolates and formae specialis mali taxonomic classification. Classical plant pathological procedures for host specificity of different Monilinia species recognized three levels of specificity, described as polytrophy, oligotrophy, and monotrophy. Most of the Disjunctoriae species are monotrophic pathogens, although some are oligotrophic. Junctoriae species are polytrophic in domesticated and wild Rosaceae and may also be found as saprophytes on other hosts, but there are reports on some level of host preference in M. fructigena and M. laxa (2). M. fructicola has a fairly similar host range to $M$. laxa, but they did not originally coexist in the same regions of the world. Biological 
specialization, the ability of a particular fungal isolate to infect and reproduce only on a particular host or group of hosts is very well documented and studied in $F$. oxysporum causing wilt diseases. More than 150 host-specific formae speciales have been described for this species, with nuclear and mitochondrial gene genealogies for eight of them. AFLP polymorphism based phylogenies have also been constructed (1).

Eight formae speciales are found in grass powdery mildew (Blumeria graminis). Detailed study of ITS regions, $\beta$ tubulin gene, and AFLP analysis showed isolates grouping according to their principal host genus and not according to geographic origin. For the AFLP marker system, authors have reported on such high variation in banding pattern that it was difficult to identify common bands (38). The same observation was noted in our analysis, in which Monilinia isolates were not grouped according to geographic origin, with the exception of four Japanese isolates which clustered together in the dendrogram. However, clear separation of apple isolates presenting forma specialis mali from all other isolates was clearly seen and supported by the high bootstrap values of the UPGMA dendrogram, PCO analysis, AMOVA statistics, and Structure clustering.

AFLP seems to be the molecular tool of choice for fungal genetic variability analysis. The results of Vakalounakis et al. (35) also showed strong correlation between AFLP haplotypes and formae speciales. The mechanisms responsible for apple specialization in $M$. laxa are not known, but they probably occur at the site of infections - stigmas, since M. laxa f. sp. mali cannot infect other hosts (5), but other host isolates can easily be grown and maintained on apple fruits (20).

Gell et al. (12) assessed genetic diversity among diverse populations of $M$. laxa isolates from different fruit production areas of peach, almond, and apricot and two isolates of M. fructigena and M. fructicola in Spain, using RAPD markers. The examined isolates were grouped in three clusters as expected: $M$. fructigena, $M$. fructicola, and M. laxa; but a further grouping of $M$. laxa isolates according to sampling place, year, or host was not observed. Our results showed host restricted specialization of isolates, since apple $M$. laxa isolates are clearly distinguished.

This is the first report that molecular marker data support the existence of biological specialization of $M$. laxa isolates for apple trees and forma specialis mali taxonomic classification. These data, combined with additional analysis, will contribute to understanding the underlying mechanisms of $M$. laxa host specificity.

\section{ACKNOWLEDGMENTS}

We thank Kazuaki Tanaka from the Laboratory of Phytopathology of the Faculty of Agriculture and
Life Science, Hirosaki University, for kindly providing isolates $2809 \mathrm{G}, 7809 \mathrm{D}, 1888 \mathrm{G}$, and 1888D. The work was supported by grant number 1000-06310162 to TG and by P4-0077 from the Slovenian Research Agency.

\section{LITERATURE CITED}

1. Baayen, R. P., O'Donnell, K., Bonants, P. J. M., Cigelnik, E., Kroon, L. P. N. M., Roebroeck, E. J. A., and Waalwijk, C. 2000. Gene genealogies and AFLP analyses in the Fusarium oxysporum complex identify monophyletic and nonmonophyletic formae speciales causing wilt and rot disease. Phytopathology 90:891-900.

2. Batra, L. R. 1991. World Species of Monilinia (fungi): Their Ecology, Biosystematics and Control. New York Botanical Garden, Mycological Society of America, Berlin, Stuttgart.

3. Byrde, R. J. W., and Willetts, H. J. 1977. The brown rot fungi of fruit: Their Biology and Control. Pergamon Press, Oxford, UK.

4. CABI/EPPO. 1991. Distribution maps of plant diseases. CAB International, Wallingford, GB.

5. Celar, F., and Valič, N. 1999. The occurrence of fungus Monilinia laxa $\mathrm{f}$. sp. mali in Slovenia. Page 514 in: 4th Slovenian Conference on Plant Protection. J. Maček, ed. Društvo za varstvo rastlin, Portorož, Slovenia.

6. Chulze, S. N., Ramirez, M. L., Torres, A., and Leslie, J. F. 2000. Genetic variation in Fusarium section Liseola from no-till maize in Argentina. Appl. Environ. Microbiol. 66:53125315.

7. Evanno, G., Regnaut, S., and Goudet, J. 2005. Detecting the number of clusters of individuals using the software STRUCTURE: A simulation study. Mol. Ecol. 14:2611-2620.

8. Fahleson, J., Lagercrantz, U., Hu, Q., Steventon, L. A., and Dixelius, C. 2003. Estimation of genetic variation among Verticillium isolates using AFLP analysis. Eur. J. Plant Pathol. 109:361-371.

9. Folkertsma, R. T., van der Voort, J. N., de Groot, K. E., van Zandvoort, P. M., Schots, A., Gommers, F. J., Helder, J., and Bakker, J. 1996. Gene pool similarities of potato cyst nematode populations assessed by AFLP analysis. Mol. Plant-Microbe Interact. 9:4754.

10. Fulton, C. E., and Brown, A. E. 1997. Use of SSU rDNA group-I intron to distinguish Monilinia fructicola from M-laxa and M-fructigena. FEMS Microbiol. Lett. 157:307-312.

11. Fulton, C. E., van Leeuwen, G. C. M., and Brown, A. E. 1999. Genetic variation among and within Monilinia species causing brown rot of stone and pome fruits. Eur. J. Plant Pathol. 105:495-500.

12. Gell, I., Larena, I., and Melgarejo, P. 2007. Genetic diversity in Monilinia laxa populations in peach orchards in Spain. J. Phytopathol. 155:549-556.

13. Holst-Jensen, A., Kohn, L. M., Jakobsen, K. S., and Schumacher, T. 1997. Molecular phylogeny and evolution of Monilinia (Sclerotiniaceae) based on coding and noncoding rDNA sequences. Am. J. Bot. 84:686-701.

14. Hughes, K. J. D., Fulton, C. E., McReynolds, D., and Lane, C. R. 2000. Development of new PCR primers for identification of Monilinia species. EPPO Bull. 30:507-511.

15. Ioos, R., and Frey, P. 2000. Genomic variation within Monilinia laxa, $M$-fructigena and $M$ fructicola, and application to species identification by PCR. Eur. J. Plant Pathol. 106:373378.

16. Lee, D. H., Lee, S. W., Choi, K. H., Kim, D. A., and Uhm, J. Y. 2006. Survey on the occurrence of apple diseases in Korea from 1992 to 2000. Plant Pathol. J. 22:375-380.

17. Majer, D., Mithen, R., Lewis, B. G., Vos, P., and Oliver, R. P. 1996. The use of AFLP fingerprinting for the detection of genetic varia- tion in fungi. Mycol. Res. 100:1107-1111.

18. Mueller, U. G., and Wolfenbarger, L. L. 1999 AFLP genotyping and fingerprinting. Trends Ecol. Evol. 14:389-394.

19. Mule, G., Gonzalez-Jaen, M. T., Hornok, L., Nicholson, P., and Waalwijk, C. 2005. Advances in molecular diagnosis of toxigenic Fusarium species: A review. Food Addit. Contam. 22:316-323.

20. Munoz, Z., Moret, A., and Bech, J. 2008. Morphological and molecular characterization of Monilinia sp. isolates and pathogenicity on apple. Agrociencia 42:119-128.

21. Nei, M., and Li, W. H. 1979. Mathematical model for studying genetic variation in terms of restriction endonuclease. Proc. Natl. Acad. Sci. USA 76:5269-5273.

22. Pritchard, J. K., Stephens, M., and Donnelly, P. 2000. Inference of population structure using multilocus genotype data. Genetics 155:945959.

23. Radišek, S., Jakše, J., and Javornik, B. 2001 Optimisation of amplified fragment length polymorphism (AFLP) analysis of hop wilt (Verticllium alboatrum and Verticillium dahliae). Acta Agric. Slov. 77:139-146.

24. Radisek, S., Jakse, J., and Javornik, B. 2006. Genetic variability and virulence among Verticillium albo-atrum isolates from hop. Eur. J. Plant Pathol. 116:301-314.

25. Restrepo, S., Duque, M., Tohme, J., and Verdier, V. 1999. AFLP fingerprinting: An efficient technique for detecting genetic variation of Xanthomonas axonopodis pv. manihotis. Microbiol. U.K. 145:107-114.

26. Rohlf, J. F. 1998. NTSYS: Numerical taxonomy and multivariate analysis system, version 2.02. Exeter Software, Setauket, NY.

27. Rosendahl, S., and Taylor, J. W. 1997. Development of multiple genetic markers for studies of genetic variation in arbuscular mycorrhizal fungi using AFLP $^{\mathrm{TM}}$. Mol. Ecol. 6:821-829.

28. Schmidt, H., Niessen, L., and Vogel, R. F. 2004. AFLP analysis of Fusarium species in the section Sporotrichiella - evidence for Fusarium langsethiae as a new species. Int. J. Food Microbiol. 95:297-304.

29. Schneider, S., Roessli, D., and Excoffier, L. 2000. Arlequin: A software for population genetics data analysis. Ver 2.000. Genetics and Biometry Lab, Dept. of Anthropology, University of Geneva.

30. Sharma, R. L., and Kaul, J. L. 1987. Blossom blight and fruit rot of apple. Indian J. Plant Pathol. 5:205-206.

31. Sharma, R. L., and Kaul, J. L. 1988. Susceptibility of apples to brown rot in relation to quantitative characters. Indian Phytopathol. 41:410-415.

32. Sisto, A., Cipriani, M. G., Tegli, S., Cerboneschi, M., Stea, G., and Santilli, E. 2007. Genetic characterization by fluorescent AFLP of Pseudomonas savastanoi pv. savastanoi strains isolated from different host species. Plant Pathol. 56:366-372.

33. Staats, M., van Baarlen, P., and van Kan, J. A L. 2007. AFLP analysis of genetic diversity in populations of Botrytis elliptica and Botrytis tulipae from the Netherlands. Eur. J. Plant Pathol. 117:219-235.

34. Travis, S. E., Maschinski, J., and Keim, P. 1996. An analysis of genetic variation in $A s$ tragalus cremnophylax var cremnophylax a critically endangered plant, using AFLP markers. Mol. Ecol. 5:735-745.

35. Vakalounakis, D. J., Doulis, A. G., and Klironomou, E. 2005. Characterization of Fusarium oxysporum f. sp. radicis-cucumerinum attacking melon under natural conditions in Greece. Plant Pathol. 54:339-346.

36. Van de Peer, Y., and De Wachter, R. 1994 TREECON for Windows: A software package for the construction and drawing of evo- 
lutionary trees for the Microsoft Windows environment. Comput. Appl. Biosci. 10:569570.

37. Vos, P., Hogers, R., Bleeker, M., Reijans, M., Vandelee, T., Hornes, M., Frijters, A., Pot, J., Peleman, J., Kuiper, M., and Zabeau, M.
1995. AFLP - A new technique for DNAfingerprinting. Nucleic Acids Res. 23:44074414.

38. Wyand, R. A., and Brown, J. K. M. 2003. Genetic and forma specialis diversity in Blumeria graminis of cereals and its implica- tions for host-pathogen co-evolution. Mol. Plant Pathol. 4:187-198.

39. Zhang, Y., Bodmer, M., and Ruegg, J. 1991 Variation in sensitivity to sterol biosynthesis inhibitors (SBI) of different isolates of Monilinia species. J. Plant Dis. Prot. 98:317-322. 